$9-8-2020$

\title{
Beyond Microaggression: Overlapping Identities in Simulated Legal Practice
}

Peggy Cooper Davis

Danielle Davenport

Brence Pernell

Follow this and additional works at: https://digitalcommons.law.villanova.edu/vlr

Part of the Law and Psychology Commons, Legal Education Commons, Legal Ethics and Professional Responsibility Commons, and the Legal Profession Commons

\section{Recommended Citation}

Peggy C. Davis, Danielle Davenport \& Brence Pernell, Beyond Microaggression: Overlapping Identities in Simulated Legal Practice, 65 Vill. L. Rev. 321 (2020).

Available at: https://digitalcommons.law.villanova.edu/vlr/vol65/iss2/2

This Article is brought to you for free and open access by Villanova University Charles Widger School of Law Digital Repository. It has been accepted for inclusion in Villanova Law Review by an authorized editor of Villanova University Charles Widger School of Law Digital Repository. 
Davis et al.: Beyond Microaggression: Overlapping Identities in Simulated Legal

2020]

\title{
BEYOND MICROAGGRESSION: OVERLAPPING IDENTITIES IN SIMULATED LEGAL PRACTICE
}

\author{
Peggy Cooper Davis,* \\ Danielle Davenport** \\ \& Brence Pernell****
}

\begin{abstract}
The authors' in-depth analyses of interactions within a simulated lawyering course expose interactive pitfalls-both in practice and in teaching-and suggest means of improving law students' and professors' professional competence.
\end{abstract}

* John S.R. Shad Professor of Lawyering and Ethics, New York University School of Law, Director, Experiential Learning Lab.

** Actor and Writer; Teaching Fellow, New York University of Law Experiential Learning Lab.

*** Adjunct Professor, New York University School of Law. 
InTRODUCTION ........................................ 323

I. The Family Practice Simulation Course . . . . . . . . . . . . . . 329

II. Interactive Analysis of a Simulated Interview . . . . . . . 332

A. Textual Analysis ........................ 333

1. Question Forms ............................ 335

2. Stutters and Meaningless Fillers .............. 336

3. Honorific Addresses...................... 337

4. Overlapping Speech....................... 338

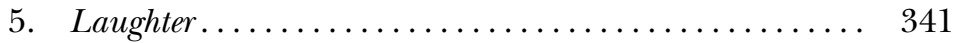

B. Participant Perspectives ................... 346

1. The Actor Perspective: The Invocation of Status. ....... 346

2. The Student Perspective: Playing Straight or Cagey........................... 348

3. The Faculty Perspective: Cultivating Multiple

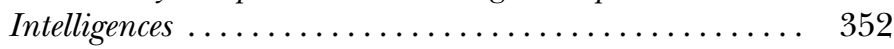

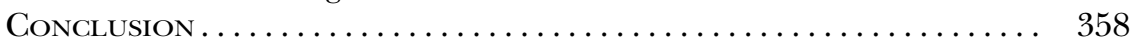

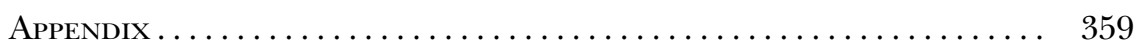




\section{INTRODUCTION}

$A_{0}$ family law simulation course meets for a final critique session: a small group of students, a few actors, and a professor around a table; a research fellow off to the side. Imagine that we mute the scene and, for a moment, that we just track body language.

We see a student and an actor with whom the student had worked in role. They are engaged in conversation-both black women of similar age. There's reciprocal laughter, animated gesturing, warmth. They've only interacted once before, in role, as lawyer and client, but there's an immediate rapport, some bond or connection that's visible here in the classroom.

We fast forward a bit to another student-actor pair in conversation. They, too, had worked in role as lawyer and client, and like the first pair, they debrief. The actor is animated and upbeat. The student is cooler in affect, but seems comfortable. At a certain point, as the actor's mouth and hands fly, something shifts for the student. Her mien grows increasingly stoic as the actor continues talking, aiming to engage her in acknowledging a shared experience that the student in fact perceived quite differently. We'll add that the actor is a white woman in her thirties, and the student a black woman in her twenties.

We unmute the soundtrack and replay the second pair. The actor's words that seem to correlate to the student's increasing chill are a description of the student by the actor- "smart . . . well-prepared . . . articulate . . . articulate"-a notable repetition to some, if not all, of the black people present. We also notice that the shift in the student's affect is clearest when the actor says the student "played high."

The actor, a member of another university's undergraduate theater faculty, gives context for the term by describing "status work" as a cornerstone of actor training. But in this moment, in this law school classroom, her phrasing has quietly obliterated any sort of collaborative, communicative bond that may have been forged between actor and student. There is none of the warmth and ease that we observed watching the first student-actor pair. And the actor has no idea.

Invariably, who we are impacts how we engage: as lawyer and client, as teacher and student, as colleagues, as humans. Our education, experience, and identities affect our interactive behavior, and they affect how (and whether) we perceive the overt and subtle behaviors of those with whom we interact. From the \#MeToo and Time's Up movements ${ }^{1}$ to companies' and institutions' renewed (albeit largely under-realized) commitments to diversity and inclusion, ${ }^{2}$ mainstream cultural standards of

1. See, e.g., Catherine A. MacKinnon, Where \#MeToo Came from, and Where It's Going, Atlantic (Mar. 24, 2019), https://www.theatlantic.com/ideas/archive/ 2019/03/catharine-mackinnon-what-metoo-has-changed/585313/ [https:// perma.cc/NM2H-SNVE] ("Sexual-harassment law prepared the ground, but \#MeToo, Time's Up, and similar mobilizations around the world-including \#NiUnaMenos in Argentina, \#BalanceTonPorc in France, \#TheFirstTimeIGotHarassed in Egypt, \#WithYou in Japan, and \#PremeiroAssedio [sic] in Brazil among them-are shifting gender hierarchy's tectonic plates.").

2. See, e.g., Tracey Lien, As Diversity Progress in Silicon Valley Stalls, Advocates Call for a New Approach, L.A. Times (June 4, 2018), https://www.latimes.com/business/ 
interaction are evolving. ${ }^{3}$ As some breathe sighs of relief and others struggle to adjust previously normative behaviors that they have only just discovered are problematic, ${ }^{4}$ the ability to discern identity-informed cues in social and professional interactions has become invaluable no matter the context or identities at play.

For this reason and others, this is an auspicious moment for improving law students' training for the interactive work that will fill their professional lives. Bar associations, law schools, and bar admission standardsetters have acknowledged the importance of clinical and simulated legal training to professional excellence. ${ }^{5}$ They have therefore made clinical

technology/la-fi-tn-diversity-fatigue-20180604-story.html [https://perma.cc/4J5AS9J9] ("Silicon Valley tech companies were pressured to share their workforce demographics, confirming what diversity advocates had suspected all along: The industry is overwhelmingly white and male. Then came the promises to do better. Tech execs penned mea culpa blog posts pledging to devote more resources to diversifying their workforces, heads of diversity were hired, employees were sent to unconscious bias training. Half a decade on, change has been slow. Attrition of women remains high. And the number of black and Latino tech workers has by some counts actually declined.").

3. See, e.g., Harassment, Equality, Power: What Leaders Said at the New Rules Summit, N.Y. Times (June 17, 2019), https:/ /www.nytimes.com/2019/06/17/business/ new-rules-summit-excerpts.html [https://perma.cc/6CPF-HRZQ] (quoting remarks by Susan Zirinsky, President of CBS News, made during her speech at the New York Times' The New Rules Summit, from June 12-13, 2019) (noting that "over the years . . . there were listeners, but no action was taken, no consequences happened, people weren't accountable. The debts of history were coming due. And so we have really put an enormous effort into fortifying real H.R. people who are listening and making recommendations, and acting, really increasing the number of people. And I think that both the \#MeToo movement and the issues of unconscious bias, they're not going to go away. You know, sometimes there's a movement and you achieve a level of success, which I think these movements are. But they're not over, and they're never going to be over. And the tectonic plates have shifted, but they're never going to lock and load, and that's O.K.").

4. The recent imbroglio surrounding former Vice President Joe Biden's touchiness on the campaign trail over the years-and refusal to apologize for behavior that made some women uncomfortable-stands as a prime example. See, e.g., Amber Phillips, Joe Biden Just Made It Clear He Doesn't 'Get' the Touching Controversy, Wash. Post (Apr. 5, 2019, 2:20 PM), https://www.washingtonpost.com/politics/2019/04/05/joe-biden-just-made-clear-he-doesnt-get-touching-controversy/ [https://perma.cc/S8Z3-6W2J].

5. See, e.g., Am. Bar Ass'n, Task Force on Law Schools \& the Profession, Legal Education and Professional Development-an Educational Continuum 54 (1992) (summarizing the history of clinics and recognizing the value of the "clinical legal education with its focus on translating the needs of society for the profession's services and skills into their educational equivalents"); $i d$. at 234 ("[I]t is now apparent that a well-structured clinical program . . . provides an important vehicle for the development of the skills of legal analysis and research. These skills can no longer be viewed as teachable only in the traditional classroom setting. . . [L] aw schools, through their clinical programs, have developed the capacity to teach other lawyering skills-those associated with practice-that had previously been considered as incapable of being taught other than through direct practice experience. The skills of 'problem solving,' 'factual investigation,' 'communication,' 'counseling,' 'negotiation,' and 'litigation' are being taught in many, perhaps most, law schools in ways that emphasize the conceptual underpinnings of 
and simulation training mandatory for law school accreditation, law school graduation, and bar passage. ${ }^{6}$ Clinical and simulation courses have mushroomed as a result, and these courses provide ideal contexts for the development of students' capacities-so necessary, in these turbulent, divided times-for communicating effectively and gracefully across identity differences.

The Family Practice Simulation ${ }^{7}$ course from which this study is drawn is taught in accordance with a methodology developed at New York University School of Law as a foundation for its pioneering simulation curriculum. ${ }^{8}$ This method is built on a presumption that excellence in legal practice requires intellectual versatility. Accordingly, it structures students' work so that their attention is regularly called to each of the five modes of analysis that we consider basic to the work of lawyers: logical analysis, sociocultural analysis, psychological analysis (understood in both interpersonal and intrapersonal terms ${ }^{9}$ ), rhetorical analysis, and ethical analysis. These modes of analysis are systematically applied with respect to each of four elements of a legal matter: facts, goals, law, and strategic interactions. ${ }^{10}$

In what follows, we reflect on how simulation courses can open the door to constructive engagement with the complex dynamics of communication across identity differences-dynamics that were dramatically at play in the exchanges described above. We will see that these dynamics are more easily exposed and addressed in contexts in which students' and teachers' attention is regularly called to all of the five modes of legal analysis and to each of the four elements of legal work.

We ground our analysis of lawyering communication across identities in two concepts that are central to developing law students' capacities for

these skills. . . Moreover, the organized instruction in these skills, in a simulated or live-client context in law schools, enables students to relate their later practice experience to concepts that they have learned in law school . . ..").

6. ABA Accreditation Standard 303(a) (3) requires students to complete "one or more experiential course(s) totaling at least six credit hours. An experiential course must be a simulation course, a law clinic, or a field placement . . . ." Ам. Bar Ass'n. Standards and Rules of Procedure for Approval of Law Schools Standard 303(a) (3) (AM. BAR Ass'N 2018-2019).

7. See infra Part I.

8. The Lawyering Method served as a basis for the expansion of NYU Law School's first year Lawyering curriculum, one of the earliest programs of its kind. For a full description, see The Lawyering Method, N.Y.U. L., https://www.law.nyu .edu/experientiallearninglab/methods/lawyeringmethod [https://perma.cc/ 4UWE-VZHW] (last visited May 8, 2020).

9. See Analyzing Every Dimension, N.Y.U. L., https://www.law.nyu.edu/node/ 29419 [https://perma.cc/8JGW-ELDH] (last visited May 8, 2020) (discussing intra- and interpersonal analysis); see also Howard Gardner, Frames of Mind: The Theory of Multiple Intelligences (1983) (discussing intrapersonal intelligence).

10. See Analyzing Every Dimension, supra note 9. 
sociocultural, psychological, and ethical analysis: microaggression and social distance.

Microaggressions-defined as "subtle, stunning, dramatic, often nonverbal exchanges which are [or are perceived as] put-downs" 11 -were named by Chester Pierce, a brilliant African American professor of psychiatry, as he described his professional life among white colleagues in an essay subtitled Thirty-Three Years of Stress. ${ }^{12}$ Pierce described the stress that came from anticipating and fearing stereotyped negative judgments. ${ }^{13} \mathrm{He}$ reported the psychic energy he had expended trying to sort stereotyped words and actions from evidence-based assessments and pondering the ambiguity of remarks that might or might not have carried stereotyped and negative judgment. ${ }^{14}$ These things, he reported, had drained his psychic energy and impaired his (nonetheless stellar ${ }^{15}$ ) professional performance throughout a long career. ${ }^{16}$ The term was introduced into the parlance of the legal academy in 1989 in an effort to explain and address the operation of unconscious bias in the legal system, ${ }^{17}$ and it has served to name and to call attention to moments when legal professionals utter or act upon stereotype-based negative assumptions. The term microaggression has come to have significant resonance beyond the legal and academic realm and is now regularly invoked to describe an insidious, unintended, often racialized (or gendered or otherwise biased) remark or behavior that implicitly attacks the competence, merit, or sense of belonging of a member of an underrepresented or disempowered group in any setting.

Work pioneered in social psychology by Claude Steele verified and expanded on Pierce's conclusion that being at risk of microaggressionwhich is to say being at risk of being negatively stereotyped-not only causes stress, but also impairs performance. ${ }^{18}$ As a result of Steele's work and the work of colleagues who followed him, the condition of being at risk of microaggression came to be known as stereotype threat and was shown to induce stress and impair performance among blacks as well as

11. Chester M. Pierce, Unity in Diversity: Thirty-Three Years of Stress 17 (1986) (unpublished manuscript).

12. Id.

13. Chester M. Pierce, Unity in Diversity: Thirty-Three Years of Stress, in BLACK Students: Psycholosocial Issues and Academic Achievement 296, 304-12 (Gordon LaVern Berry \& Joy Keiko Asamen, eds. 1989).

14. Id.

15. Pierce was Professor of Education and Psychiatry at Harvard Medical School. He was the first African-American full professor at Massachusetts General Hospital, and was president of both the American Board of Psychiatry and Neurology and the American Orthopsychiatric Association. He was a fellow in the American Academy of Arts and Sciences. He published over 180 books, articles, and reviews.

16. Pierce, supra note 13, at 304-12.

17. Peggy Cooper Davis, Law as Microaggression, 98 YALE L.J. 1559, 1568-76 (1989) [hereinafter Davis, Law as Microaggression].

18. Steele et al., Young, Gifted and Black 123-24 (2004). 
other groups susceptible to stereotyped judgment. ${ }^{19}$ Subsequent research in social psychology, also involving Steele and his collaborators, broadened Pierce's insight that those subject to negative stereotyping are at risk of threat. ${ }^{20}$ They observed that there is mutual anxiety and stress in crossgroup encounters. ${ }^{21}$ This newer research, sometimes using the term "identity threat," posited that people who are aware that they might be thought to hold negative stereotypes experience anxiety that mirrors the anxiety of those who are aware that they might fall victim to negative stereotyping: they function in cross-group settings under threat of being considered bigoted. ${ }^{22}$ This hypothesis was supported by findings that in crossgroup settings the two groups maintained a social distance that was hypothesized to be motivated by mirrored states of mind: the stereotypethreatened group's anxiety about being judged in accordance with a negative stereotype, and the stereotyping-threatened group's anxiety about committing (or falsely being perceived as having committed) microaggressions. ${ }^{23}$

The sum of all of this research and speculation is that cross-group discourse can be fraught with stress. ${ }^{24}$ And it is a fact of professional life that most discourse crosses group lines of some sort-lines of gender, race, family status, ideology, sexual identity or preference, nationality, region, religion, or something we haven't thought to mention. To return to the moment from class, it is likely that the first pair was more at ease as a result of shared identities. ${ }^{25}$ And it is likely that the second student perceived the actor's insistence on her articulateness and high status as microaggressions grounded in stereotypes of black intellectual inferiority and servility. ${ }^{26}$ At the same time, it is just as likely that the second actor

19. See id; see, e.g., Claude Steele \& Joshua Aaronson, Stereotype Threat and the Intellectual Test Performance of African American Students, 69 J. Personality \& Soc. Psychol. 797 (1995) (documenting the phenomenon with respect to African American students); Claude Steele, Stereotype Threat and Women's Math Performance, 35 J. Experimental Soc. Psychol. 4 (1998) (documenting the phenomenon with respect to female students).

20. See generally, e.g., Philip Goff, Claude Steele \& Paul G. Davies, The Space Between Us: Stereotype Threat and Distance in Interracial Contexts, 94 J. Personal. \& Soc. Psychology 91 (2008).

21. See id.

22. See id.; see also id. at 15.

23. See id.

24. See Phillip Atiba Goff et al., supra note 20.

25. See Katharine H. Greenaway, et al., Shared Identity Is Key to Effective Communication, 4 Personality \& Soc. Psychol. Bull. 171 (2015).

26. See, e.g., Lynette Clemetson, The Racial Politics of Speaking Well, N.Y. TImes (Feb. 4, 2007), https://www.nytimes.com/2007/02/04/weekinreview/04clemetson.html [https://perma.cc/A3Z3-U74X] ("When whites use the word ['articulate'] in reference to blacks, it often carries a subtext of amazement, even bewilderment. It is similar to praising a female executive or politician by calling her 'tough' or 'a rational decision-maker.'”). Underlying the regular discomfort with the word, articulate, is the fact, for example, that not too long ago, research findings revealed that, among other stereotypes, nearly a third of white people 
perceived herself as delivering a complimentary and apt observation from one individual to another in a situation she would have handled no differently had the student been white. ${ }^{27}$

This aperture in the second pair's experience of a single shared moment will be explored in the following account of the use of experiential learning techniques in training lawyers to work across professional and personal identities. This work is a subcategory of-and inseparable from-a more comprehensive project of training students for interpersonal and intrapersonal intelligence and for socially and professionally re-

stereotyped black people as unintelligent. Phillip Goff et al., Not Yet Human: Implicit Knowledge, Historical Dehumanization, and Contemporary Consequences, 94 J. PerSonality \& Soc. Psychol. 292 (2008). Today those stereotypes remain intact and are often manifested as microaggressions. David R. Williams \& Ruth Williams-Morris, Racism and Mental Health: The African American Experience, 5 ЕтнNicity \& Health 243 (2000). A more recent study found that racist stereotypes persist as a part of the black American experience, in significant part because old racial prejudices have transformed into subtle, modern-day biases that project a false notion that society has moved beyond race issues. Derald Wing Sue, Microaggressions in Everday Life: Race, Gender, and Sexual Orientation (2010). For a more recent personal account of the legacy of microaggressions and stereotypes with which black women contend, including that of the "angry black woman," see generally Brittney Cooper, Eloquent Rage (2018).

Compounding the likely effect of the actor's statements, the law, law schools, and the legal profession, as a whole, often prove to be fertile grounds for such microaggressions. See, e.g., Davis, Law as Microaggression, supra note 17. Indeed, the racial slights are not always subtle. Around the time that Student B was in this simulation, for example, the late Supreme Court Justice Antonin Scalia remarked during an oral argument: "There are those who contend that it does not benefit African Americans to get into the University of Texas where they do not do well, as opposed to having them go to a less-advanced school, a slower-track school, where they do well." David G. Savage, Justice Scalia Under Fire for Race Comments During Affirmative Action Argument, L.A. Times (Dec. 10, 2015, 2:41 PM), https://www.la times.com/nation/la-na-scalia-race-20151210-story.html [https://perma.cc/H67A$\mathrm{H} 79 \mathrm{~F}]$. Justice Scalia cited a brief that, according to him, "pointed out that most of the black scientists in this country . . . come from lesser schools" where they do not feel they're being pushed in classes "that are too fast for them." Id. Not long thereafter, a highly regarded law school professor at the University of Pennsylvania, Amy Wax, known for her anti-affirmative action positions, asserted as evidence in a public lecture-titled, "The Downside of Social Uplift"-that she had never "seen" a black student "graduate in the top quarter of the [Penn Law School] class and rarely, rarely in the top half." Derek Hawkins, Penn Law Professor Who Said Black Students Are 'Rarely' in Top Half of Class Loses Teaching Duties, WAsH. Post (Mar. 5, 2018), https://www.washingtonpost.com/news/morning-mix/wp/ 2018/03/15/penn-law-professor-who-said-black-students-rarely-perform-well-losesteaching-duties/?utm_term=.bf4fc7c81e45 [https://perma.cc/2CNA-A7L4].

27. Cf. Tori DeAngelis, Unmasking 'Racial Microaggressions, 'Ам. Psychol. Ass'N (Feb. 2009), https://www.apa.org/monitor/2009/02/microaggression [https:// perma.cc/8AFJ-TWMB] (summarizing the work of social psychologists and quoting Columbia University psychologist Derald Wing Sue: "It's a monumental task to get white people to realize that they are delivering microaggressions, because it's scary to them .... It assails their self-image of being good, moral, decent human beings to realize that maybe at an unconscious level they have biased thoughts, attitudes and feelings that harm people of color."). 
sponsible legal practice. ${ }^{28}$ In what follows, we pursue two lines of inquiry. One is an exploration of how distinct modes of analysis and assessmentprominently including multilayered critique and discourse analysis-maximize opportunities for students' inter- and intrapersonal development. The second explores the complexity of multilayered critique as teacher, student, and actor alike navigate the very inter- and intrapersonal dynamics that the process illuminates.

We begin by describing the simulation course, the exercise within it that is the focus of this Article, and the role of actors within the course. We then provide in-depth (but necessarily partial) analyses of two students' performances in the exercise-one textual and one based on participant and faculty critiques. Through these analyses, we demonstrate the usefulness of layered formative critique and the relevance of concepts drawn from both sociolinguistic study and social distance theory to nurturing students' competence for the necessarily and importantly interactive work of lawyering. The Article concludes with a discussion of some of the difficulties students and faculty face in navigating what can be a highly personal and subjective dimension of professional training.

\section{The Family Practice Simulation Course}

Our case study is set in New York University School of Law's Family Practice Simulation course, which is designed to give students contexts for wrestling with complex legal principles while they are immersed in the kinds of interactive dramas within which those legal principles are interpreted and reformed. The course aims to give students a substantial introduction to the field of family law and exists in an alternate version that equally privileges questions of professional responsibility. At heart, the mission of either variation is to offer students the opportunity to lawyer within a pedagogical framework that emphasizes the need for intellectual versatility and builds habits of self-awareness and process evaluation that should serve them throughout their academic and legal careers. ${ }^{29}$ A semester is too short to build such career-long habits (or disrupt lifelong ones); the pace of the course is swift, and the work involved is intense. Working within it requires a kind of openness and sensitivity to the other that may run counter to the students'-and the teachers'-dominant public modes. The course nonetheless provides an important opportunity within the law school curriculum for students and faculty to exercise new muscles and perhaps discover strengths, weaknesses, and possibilities not previously explored relative to their professional pursuits and developing professional identities.

28. The larger project is described at Experiential Learning Lab, N.Y.U. L., http:/ /www.law.nyu.edu/experientiallearninglab [https://perma.cc/5CKZ-G9CF] (last visited May 8, 2020).

29. The course is designed so as to be consistent with the Lawyering Method pioneered at NYU Law School, discussed infra Part II in more detail. 
The course is taught within the contexts of two fictional simulations. In the first, an unmarried same-sex couple seeks legal advice on the benefits and penalties of marriage and other civil status, domestic partnership, and contractual options available in their state. The second simulation revolves around a child welfare proceeding that is brought when Jacob, an unvaccinated four-year-old, wanders off while under the care of an octogenarian great-aunt during his single mother's workday. We focus this Article on the second simulation and on questions of gender, race, and social status that emerge within it.

A more detailed account of the facts of the second simulation is necessary background for understanding our findings. When the child wanders off from his great-aunt's care, he is picked up by a police officer and funneled into the foster care system before the mother has a chance to intervene. The mother is a twenty-five-year-old single woman whose parents immigrated to the United States from Liberia. She has heard and read a great deal about the effects of childhood immunizations and refuses to have her child vaccinated. The immigrant great-aunt has always cared for the child while his mother is working. She is a retired nurse whose heavily accented speech sometimes results in an underestimation of her abilities-although in this case, her prescribed pain medication and customary afternoon glass of sherry emerge as more salient details as the student-lawyers evaluate the charge of neglect. The mother is hesitant for economic, emotional, and cultural reasons to modify the caretaking arrangement with her great-aunt.

In role as lawyers for the mother, for the child, or for the child welfare agency, students investigate the facts of the case, research relevant law, consult with experts, and conduct a hearing to determine whether the child will remain in foster care pending the outcome of a neglect proceeding. At each stage, their work is subjected to self-critique and critique by peers and faculty. Each student completes a structured written critique form assessing another student's performance and a structured written critique of his or her own performance. Students share these forms with the professor and with the critique partner. The actor completes a similarly structured written critique form that she provides to the professor. The professor then meets with students in small groups to review their performances and critiques. ${ }^{30}$ In the final class meeting, under the guidance of the professor, the full class and the actors interact out of role for the first time. For this omnibus critique session-the session from which the opening excerpt was drawn-students' in-role performances are once

30. The design of these formats is a complex business, worthy of an article in itself. We say here simply that we want to guide participants to respond in ways that are (1) relevant to each of the interactive dimensions we want to call to students' attention for critical review and (2) descriptive, rather than didactic, with respect to the students' performances. The (constantly evolving) format for soliciting actor responses in the exercise under study is on file with the authors. 
again collaboratively critiqued with everyone participating in a review of the entire simulation.

Actors working in the course assume a complex range of responsibilities. They must work improvisationally, but without deviating from the simulation's facts in ways that would alter the legal issues at play. They must respond as their character realistically might respond to the students' behavior. At the same time, the actors must moderate the demands they place on students so as to mete out challenges at the students' "growing edge"- that is, in a zone within which the students are challenged but not pushed beyond their (ever growing) capacities. ${ }^{31}$ And they must monitor and recall the students' successes and perceived missteps for future report and critique. They are, in a very real sense, actor-teachers, and in most cases have been formally trained as such.

Student simulation performance should not be judged exclusively or unquestioningly on the basis of actor response. This is so for at least three reasons: (1) At times the actor will not have a full understanding of legal considerations that drive a student's behavior. (2) There are times when causing discomfort to an interview counterparty is strategically appropriate, and even a well-trained simulation actor may not be able to distinguish strategy from lack of skill. And (3) a simulation actor cannot be entirely objective about his or her own contributions to any discomfort or miscommunication that occurs during an in-role interaction. As a result, the actor's responses may not reflect sufficient self-consciousness about the tone and effect of his or her performance. Due to these factors, the unscreened use of protocols for actors' assessments of student performances can make the assessment process inappropriately rigid and formulaic.

This last point warrants some elaboration. Experts in medical education have developed techniques over many years for using actors in role as "standardized patients" to both engage and assess student performance. ${ }^{32}$ In this work, medical education has been years ahead of legal education. ${ }^{33}$ Medical educators have found that working with "standardized patients" has the benefit of making simulation exchanges more easily assessable and more demonstrably beneficial. ${ }^{34}$ Actors are trained to manifest certain be-

31. L.S. Vygotsky, Mind in Society: The Development of Higher Psychological Processes 82 (1978) (using the term "Zone of Proximal Development").

32. See, e.g., Yedidia et al., Effects of Communications Training on Medical Student Performance, 290 JAMA 1157 (2003) (recognizing the positive effects of experiential learning techniques such as, for example, the use of standardized patients to improve medical students' communications skills).

33. See, e.g., Amitai Ziv et al., Simulation-Based Medical Education: An Ethical Imperative, 78 ACAD. MED. 783, 784 (2003) (noting that " $[\mathrm{t}]$ oday, it is common for students to do their first injections on an orange, practice suturing on pieces of cloth, rehearse medical interviews while role playing, or practice physical examination on simulated (standardized) patient-actors").

34. See Howard S. Barrows, An Overview of the Uses of Standardized Patients for Teaching and Evaluating Clinical Skills, 68 ACAD. MED. 443, 443-45 (1993) (discussing the many values of simulated patients over actual patients as teaching and assessment tools in the classroom). 
haviors and are given multiple choice and yes/no forms on which to record student responses to those behaviors. ${ }^{35}$ However, not unsurprising is the potential for the kind of standardization that this method requiresboth of the simulated patients' performances and of the simulated patients' assessment criteria-to constrain deep learning and encourage standardized, rather than situation-specific and patient-specific, student responses. ${ }^{36}$ This is significant because, as suggested by recent efforts to ameliorate racial disparities in care by targeting medical curricula, acknowledgement of bias and sensitivity to diverse individual experience-in medicine as in law-can literally be a matter of life or death. ${ }^{37}$

\section{Interactive Analysis of a Simulated Interview}

To illuminate the benefits and challenges of simulated learning in practice, we report the experiences of two black students, one male (A or Student A) and one female (B or Student B), who were assigned to represent the child welfare agency in the vaccination exercise and required, in the course of that representation, to interview an actor working in role as the agency's supervising social worker. ${ }^{38}$ The actor, a white woman, was told that in role she would be Susan Farrow, a conscientious social worker fearful for the safety and welfare of children-fearful lest she or her agency discover that a child whom they might have saved was killed or seriously injured. In role, she was to be both consciously unbiased and unconsciously affected by the fact that she had perceived so much deprivation, and seen so many damaged children, in the course of many years of service in impoverished communities of color. ${ }^{39}$

While we intentionally introduced fictional Susan Farrow's bias into the scenario, it was left to the students to decide what their in-role stances would be. As we will explain below, both A and B were ambivalent about representing the child welfare agency, for out of role each of them

35. See id.

36. Have you ever noticed that in some situations, doctors tend to all say the same words?

37. See, e.g., Lundy Braun \& Barry Saunders, Avoiding Racial Essentialism in Medical Science Curricula, 19 Am. Med. Ass'n J. Ethics 518 (2017); Lisa A. Cooper \& Neil R. Powe, Commonwealth Fund, Disparities in Patient Experiences, Health Care Processes, and Outcomes: The Role of Patient-Provider Racial, Ethnic, AND LANGUaGe Concordance (2004), http://drstokesfoundation.org/images/ cooper_raceconcordance_753.pdf [https://perma.cc/XN5T-LP2V]; Ass'N AM. Med. Colls., Achieving Health Equity: How Academic Medicine Is Addressing the Social Determinants of Health (2016), https://store.aamc.org/download able/download/sample/sample_id/78/ [https://perma.cc/SG77-W7NS].

38. To do so, we draw on classroom observations, personal interviews, and video recordings of simulations, all on file with the authors.

39. Out of role, the actor was the daughter of a Texas child welfare worker. She, too, was suspicious of bias and paternalism in the child welfare system, but she had genuine sympathy for the perspective of a dominant race, middle class professional who consistently perceived shortfalls in the parenting of lower- and workingclass people of color. 
thought the child welfare system to be prone to racial bias and disrespectful paternalism. Nonetheless, both students presented as engaged, conscientious, and astute participants in the simulation, and both were well prepared for their interview with Farrow.

Before presenting our findings, we acknowledge a factor that is likely to have skewed the results of the textual analysis and the actor critique. We learned during the critique process that a teacher error in the studentfacing materials had led Student B-but not Student A-to believe that the social worker was affiliated with counsel for the child and had conducted a study of the mother's home. The simulation had been designed-and was understood by Student A-such that the social worker was affiliated only with the child welfare agency (A and B's client) and had neither direct experience with the mother nor direct knowledge of her living arrangements. Student B, working from her misimpression of the social worker's knowledge base, reported that she had felt impatient with the social worker and thought her "unprepared"-either in role or out of role. Some of the findings we report below can be attributed to this frustration. Despite this difficulty, we found A's and B's performances, and the differences between them, worthy of close examination.

In the following section, we borrow tools of sociolinguistics to unpack the differences in how the two students personalized and executed the lawyering task to which they had each been assigned. In subsequent sections, we will deepen the analysis as we report the results of multi-layered actor, student, and faculty critique of the students' performances.

\section{A. Textual Analysis ${ }^{40}$}

Conversational events have been categorized, counted, and interpreted by scholars of sociolinguistics in efforts to draw conclusions about the purposes and/or the effects of participants' linguistic choices. ${ }^{41}$ These events, or linguistic markers, are useful but imperfect measures of simulation performance. One must be careful to avoid relying on generalizations about the meaning of linguistic markers, for research has confirmed the intuition that their meanings are context dependent rather than consistent. ${ }^{42}$ Nonetheless, linguistic markers can signal mental states that subtly influence the course of conversation and how it is understood. ${ }^{43}$

40. The primary sources of the textual analysis are written transcripts of the simulations, which are on file with the authors. The analysis is informed by a review of accompanying simulation videos. A transcription guide explaining the coding used in the quoted transcript portions appears in the Appendix, infra.

41. See generally, e.g., J. Maxwell Atkinson, Structures of Social Action (Studies in Conversation Analysis) (1985); The Handbook of Conversation Analysis (Jack Sidness \& Tanya Stivers, eds. 2013).

42. Deborah Schiffrin, Discourse Markers 3-5 (1987).

43. See, e.g., Peggy Cooper Davis, Law and Lawyering: Legal Studies with an Interactive Focus, 37 N.Y.U. L. REv. 185, 187 (1992) [hereinafter Davis, Law and Lawyering] (reviewing the "language of simulated lawyer-client interviews in an effort to 
We do not routinely document the occurrence and frequency with which markers occur in students' simulation work, as time does not permit it. We do, however, find it useful to code student performances in certain cases in order to acquaint ourselves with quantifiable patterns in the communication of student lawyers and their interlocutors. Familiarity with these patterns gives us more concrete and objective vocabularies for critiquing student work and allows students to develop a deeper and more specific awareness of their own habits. This analysis also provides insight into the subtler manifestations of a student lawyer's stance or strategy and an interlocutor's response to it. ${ }^{44}$ In reporting the results of our linguistic tracking, we proceed with modesty and care. We do not undertake sociolinguistic research; instead, we use the language of sociolinguistics to name and categorize student behavior while drawing no broad conclusions regarding the significance of particular markers.

For purposes of this study, we coded for and considered (1) question forms, (2) stutters and fillers, (3) honorific address, (4) overlapping speech (including both interruptions and listening responses), and (5) laughter. We looked at question forms in an attempt to distinguish between what Erving Goffman described as a state of inquiry versus a state of talk. ${ }^{45}$ We posited that closed and leading questions would create a sense of inquiry or interrogation and that open and non-leading questions would signal a more collaborative and conversational stance of talk. We looked at stutters and fillers as rough markers of discomfort and hypothesized that their absence or low frequency would imply comfort and that their relative infrequency might signal conversational dominance. We considered forms of honorific address to indicate deference or respect. With overlapping speech, we tracked interruption as a form of conversational dominance, and we examined verbal listening responses in an attempt to gauge the quality of attention paid to a conversational partner. We also explored the role of listening responses in encouraging or discouraging the other's speech. Finally, we looked to mutual laughter as a

expose unconsidered ways of interacting" and finding that "people in the role of lawyers assumed a decidedly dominant role in interactions with their clients. They controlled the flow of topics and, after the initial telling of the client's story, talked more than their clients. People in the role of clients behaved consistently with the assumption of lawyer-dominance. They spoke more haltingly, used more hedges, and made more frequent use of other linguistic forms associated with tentativeness. Despite these rather consistent signs of attorney-dominance and client-deference, it was possible to identify interactive patterns that distinguished relatively controlled and relatively open interviewing styles.").

44. Davis, Law and Lawyering, supra note 43; Peggy Cooper Davis, Performing Interpretation: A Legacy of Civil Rights Lawyering in Brown v. Board of Education, in Race, Law, and Culture: Reflections on Brown v. Board of Education 23 (1997) (reviewing, e.g., pronoun uses as markers of affiliation); Peggy Cooper Davis, Contextual Legal Criticism: A Demonstration Exploring Hierarchy and Feminine Style, 66 N.Y.U. L. Rev. 1635 (1991) (identifying language patterns associated with gender and with status).

45. Erving Goffman, Forms of Talk 140 (1981). 
possible sign of comfortable rapport (understanding that laughing alone might signal either comfort or discomfort).

\section{Question Forms}

A and B used markedly different question forms. A's questions were less frequent and far more likely to be open, whereas B's questions were not only greater in number but also more often leading and closed. B was predominantly seeking confirmation through her closed questions, and to a certain extent through her open questions as well. Only seven of the thirty-seven questions she posed fell in the latter category and they frequently presented alternatives-"And so did you find issues with that psych evaluation or you just would like to have another?"- -or were phrased in some other restrictive or conversationally controlling way"Um, do you have any specific goals or issues that you'd like to discuss that are different from the things that I've already stated?" Another version of this question might have landed as an engaging invitation to collaborate, but instead B narrowed her field of inquiry in potentially strategic and likely inhibiting ways. Four of the five remaining open questions involve phrasing variations of "what would you be looking for" in various contexts that ranged from probing to authority-challenging.

A asked fewer questions than B (thirty-four as compared to thirtyseven), but in light of the relative length of the two interviews $(2,891$ words spoken by A and 1,789 by B), the greater rapidity of B's questions (10.34 per 500 words, as opposed to A's 5.88 per 500 words) suggests an interrogative rather than a collaborative stance.

Table 1: Question Form Counts per 500 Words

\begin{tabular}{|l|l|l|l|l|}
\hline & A & B & SW with A & SW with B \\
\hline Total Questions & 5.88 & 10.34 & 0.65 & 0.63 \\
\hline & & & & \\
\hline Open Questions & 2.42 & 1.96 & 0.33 & 0.16 \\
\hline Closed Questions & 3.46 & 8.38 & 0.33 & 0.10 \\
\hline Leading Questions & 3.11 & 6.71 & 0.43 & 0.16 \\
\hline Non-Leading Questions & 2.77 & 3.63 & 0.22 & 0.48 \\
\hline
\end{tabular}

While fewer in number, A's questions were often more extended in length. Student A used more words to build conversational bridges and elicit the social worker's buy-in to what he presented as their shared stance and strategy. He seemed to find value in allowing the social worker room to contribute on her own terms. Here, for example, he gave the social worker frames for developing alternative scenarios: 
A: Like what's the process after the investigation?

If, for example, if we say

if the home visit's done and they say ^okay, this is no, this is not a safe space for Jacob. ((NODDING))

These are things to-so what's, /what's that look like?

And then what does that the process look like

if they are do the home visit and say

this is a safe space for Jacob.

In contrast, B posed more pointed questions, framed more narrowly. Note the difference in how she pursues the same line of questioning:

B: Okay, and if you, um, if the mother maintained her position that she would like her child to remain in Oretha's care and you go forward with an investigation and the investigation, um, is positive, no negative results come from that, would you be $\wedge$ open to then allowing him ((NODDING)) to return to her care?

Where Student A sought the social worker's perspective on next steps through three open questions, Student B used almost as many words (fiftyfive to sixty-nine with more stuttering on the part of A) to ask a single yesor-no question. Student A opens the door to the social worker adding something he'd not thought of, while B seeks only confirmation. It's as though A set out to assemble a puzzle from scratch with the social worker and $\mathrm{B}$ came in almost done, with the clear contours of just a few missing pieces.

\section{2. $\quad$ Stutters and Meaningless Fillers}

We regarded a stutter as a speaker's repetition of a letter, word, or sentence fragment in a way that did not contribute intentionally to his or her meaning. We predicted that stutters would signal speaker discomfort or nervousness ${ }^{46}$ although we understood that they could also be signs of exuberance, sarcasm, or some other state of a speaker's mind. Similarly, when a speaker's talk contained words that marked hesitations or pause points rather than contributions to the meaning of his or her talk, we coded them as fillers. A distinction was made between meaningless fillers (e.g., "uh" or "um") and utterances of actual words that seemed to serve only or primarily as fillers (e.g., "Why don't we, like, go into town?"). We predicted that fillers would also signal speaker discomfort or nervous-

46. See, e.g., William Safire, Watching My Language: Adventures in the WORLD TRADE 116-17 (1997) (recognizing that modern linguists sometimes refer to stutters as "hesitation forms" that are interjected when the speaker is groping for words or at a loss for the next thought). 
ness, ${ }^{47}$ although we understood that they might at times have other meanings.

The actor in role as a social worker stuttered much more than either student. Still, her stutter occurred considerably more frequently with B than with A. Student B stuttered less than A and gave the impression of being a very confident communicator, although she used considerably more fillers than her male counterpart. Both used fewer fillers than the actor in role as social worker.

Table 2: Stutter and Meaningless Filler Counts per 500 Speaker Words

\begin{tabular}{|l|l|l|l|l|}
\hline & A & B & SW with A & SW with B \\
\hline Stutters & 4.15 & 1.40 & 10.20 & 14.91 \\
\hline Meaningless Fillers & 11.58 & 20.68 & 18.00 & 25.38 \\
\hline Verbal Fillers & 1.97 & 8.38 & 4.34 & 10.31 \\
\hline
\end{tabular}

Some stuttering and hesitation are to be expected in the simulation setting. Students are trying on professional roles that are new to them under pressure of observation, critique, and grading. Actors, once again, must simultaneously portray a character, recall complex sets of facts and improvise from them, measure out challenges for students, and critique the students' performances. Nonetheless, the pattern here suggests that the social worker (in role, out, or most likely on both levels) was more at ease with A than with B and that B spoke with more confidence than $\operatorname{did} \mathrm{A}$.

\section{Honorific Addresses}

We observed how the student lawyers addressed or referenced the social worker, noting when a reference was honorific (as in "give me your professional opinion"). We interpreted honorific reference as a collaborative and rapport-building conversational move. (With these students, there were no examples of honorific reference that we interpreted as being sarcastic and therefore neither collaborative nor rapport-building.)

47. See, e.g., Paul R. Timm \& Sherron Bienvenu, Straight Talk: Oral ComMUNicAtion FOR CAREer Success (2011) (explaining that individuals filling the air with non-words and sounds is a sign of nervousness; they fear silence and experience speaker anxiety or are searching for the next word); see also Joey AsHer, SELling AND Communication Skills fOr Lawyers 206 (2005) ("Perhaps no profession has uttered more 'ums' or 'uhs' than the legal profession. Such words are a clear indication that the speaker's style is halting and uncertain. Eliminate these filler words. The lack of 'ums' and 'uhs' alone can make you sound more confident."). 
Table 3: Use of the Words "Professional" or "Expert"

\begin{tabular}{|l|l|l|}
\hline & A & B \\
\hline Total & 6 & 2 \\
\hline Count per 500 Speaker Words & 1.04 & 0.56 \\
\hline
\end{tabular}

Student A used honorific references almost exactly twice as frequently as Student B considering the respective interview lengths, and each of his references to the social worker's expert opinion or professional experience seemed to demonstrate respect and deference to the wisdom of her experience. While A used both the word "professional" and "expert," B never used the word "expert." Her first invocation of professionalism seems to suggest that the social worker's preceding remarks have not been professional:

SW: $\quad \mathrm{Ah}=$, you know $=.$.

it can be $\wedge$ concerning \what are the sort of, you know, lots of things can happen, um,

that are out of the ${ }^{\wedge}$ control $=$ of $\wedge$ anyone, ah, /in a home, being like, you know,

$\wedge^{\wedge}$ natural disasters or $\wedge^{\wedge}$ fires, or

((KNOCKS ON TABLE) )

$<$ knock on wood, $>$ /if someone should $<$ break into your house, $>$ something like that.

So we just want to make sure that that

he is having the best possible care.

B: Okay . . um . .

So ...

I guess I would be interested in learning $\wedge^{\wedge}$ more about like your professional opinion about the chances of her >exposing Jacob to harm<

B follows up on the social worker's comments by refocusing the social worker on the question at hand. Student B emphasizes that her interest is only in the social worker's professional opinion and that she is not inclined to indulge or encourage this more abstract discussion of things that can happen in a home.

\section{Overlapping Speech}

We coded overlapping speech, distinguishing between listening responses on the one hand, and simultaneous speech with independent verbal content on the other. Within the category of listening responses, we distinguished between meaningless utterances like " $\mathrm{mhm}$ " and verbal af- 
firmations like "right," "okay," and "yeah." We predicted that in the context of the student lawyers' interview of the social worker listening responses were likely to serve to encourage or affirm what another speaker had said (or was saying), although they might also express disagreement or discouragement.

Table 4: Listening Response Count per 500 Speaker Words

\begin{tabular}{|l|l|l|l|l|}
\hline & A & B & SW with A & SW with B \\
\hline $\begin{array}{l}\text { Meaningless Listening } \\
\text { Responses }\end{array}$ & 10.55 & 7.55 & 0.69 & 1.17 \\
\hline $\begin{array}{l}\text { Verbal Listening } \\
\text { Responses }\end{array}$ & 22.14 & 15.65 & 4.99 & 2.38 \\
\hline
\end{tabular}

A uttered both verbal and meaningless listening responses at a significantly higher rate than did B, uttering a total of 32.69 per 500 words, as opposed to B's 23.20. B's listening responses were more percussive; fortyfour of the fifty-six were a brisk "okay." Additionally, she used the word "right" nine times and "yeah" once. A, on the other hand, said "right" fifty-three times, "okay" thirty-nine times, and "yeah" twenty-one times. His speech also contained up to five uses each of more explicitly affirming utterances: "absolutely," "yes," "perfect," "correct," "I see," and "definitely." These counts provide further evidence of the sympathetic, collaborative dynamic of A's interview and the crisp, professional, no-nonsense character of B's interview. ${ }^{48}$

When simultaneous speech had independent content, we attempted to distinguish between speech that interrupted or disrupted a speaker's turn and speech that embellished the statement of the speaker who had the floor. We define an overlapping speaker turn consisting of more than an affirmation or meaningless utterance as an interruption. The advanced students whose work we study here were predictably and appropriately schooled to the pitfalls of interrupting a conversational partner. Between the two interviews, there were no clear-cut instances of interruption; in fact on more than one occasion, speaker overlap took the shape of a congenial and collegial collaboration. Notwithstanding, there were some instances of overlap that suggested a communicative power struggle comprised of a series of near interruptions.

48. See Christina Wasson, Integrating Conversation Analysis and Issue Framing to Illuminate Collaborative Decision-Making Activities, 10 Discourse \& Comm. 378 (2016). 
Table 5: Incidents of Overlapping Another's Talk

\begin{tabular}{|l|l|l|l|l|}
\hline & A & B & SW with A & SW with B \\
\hline Total & 6 & 7 & 13 & 9 \\
\hline Meaningless Utterances & 0 & 1 & 0 & 2 \\
\hline Affirmations & 2 & 3 & 6 & 5 \\
\hline New Thought & 4 & 3 & 7 & 2 \\
\hline Count per 500 Words & 1.04 & 1.96 & 1.41 & 1.43 \\
\hline
\end{tabular}

Seemingly collaborative overlap is illustrated by this exchange between Student A and the social worker in which bracketed aligned text corresponds to simultaneous speech: ${ }^{49}$

SW: The only reported incident is the doc[tor]

A:

[The doctor] ((NOD-

DING))

SW: who did the [vaccination. Yes.]

A: [The vaccinations.]

Correct ((NODDING)).

SW: ^But, um ...

A: You're just saying [from your] . ((GESTURING))

SW:

[From my, my], my, from ((GESTURING))

A: opinion.

SW: my perspective,

$<$ ah, you know if you have $>$ a four-year-old child

in a home without $\wedge^{\wedge}$ supervision $=$

As this excerpt from the transcript demonstrates, Student A and the actor had developed a conversational relationship (by only the tenth of fifty-one pages of transcript) that made them willing and able to develop an idea jointly. The repetition of identical words stands out-we define these turns not as interruptions, but rather verbal gestures of support in the form of affirmation or reiteration of key words. Student A echoes and privileges the social worker's speech in his start at a restatement, but he is quick to cede the turn back to the social worker so that she can make her point in her own words, on her own terms. For A and the social worker, finishing each other's sentences enhances the sense of their working collaboratively toward a common goal and reflects the largely collaborative, constructive dynamics of the interview on the whole.

By contrast, the social worker and Student B seemed at times to be vying for the floor:

49. The text that appears in brackets and in line (vertically, between the two speakers) occurred simultaneously. 
B: Okay . . um . .

So ...

I guess I would be interested in learning $\wedge^{\wedge}$ more about

like your professional opinion about the chances of her >exposing Jacob to harm< /if he was returned \to her care, like, um, without any $\wedge^{\wedge}$ changes being made [to like] her day-to-day

SW:

[Mmh.]

B: and her um ...

SW: I think if you're, like if [there were no changes]

B:

[consumption of medication] [etcetera.]

SW:

/With, with Oretha?

[Yeah.]

B: Yes

In brief, the social worker interjects, eager to answer a question that hasn't been fully articulated. It is interesting to note that this discussion follows the excerpt presented in the honorific address section; the lawyer's extended statement of what she is interested in hearing may be plausibly read as an effort to refocus the social worker on the matter at hand in a way that dismisses what's come before (the social worker's recitation of possible hazards to children and people in general). The social worker's meaningless listening response of "mmh" is not an interruption given its lack of verbal content and the fact that the lawyer continues speaking, but her speech after the lawyer's "um ..." in which she jumps in assertively during a brief mid-sentence pause to seek clarification on a point B hasn't yet finished making constitutes a borderline interruption. The social worker seems to be asserting herself verbally in this instance, but undercuts herself by not being prepared to contribute substantively when she does.

\section{Laughter}

We coded laughs with the notation @, each notation representing the number of "breaths" of laughter within a single instance. We also recorded the number of episodes of laughter in each interview as a broader category to encompass connected instances of unilateral or shared laughter interspersed with speech. We anticipated that shared laughter might signal comfort and unilateral laughter might signal discomfort.

The social worker laughed more than the student in each case. Her laughter with Student B was less than a third as frequent as her laughter with Student A. Her laughter with Student A exceeded her laughter with Student B in terms of breaths, instances, and episodes. 
Table 6: Laughter per 500 Words

\begin{tabular}{|l|l|l|l|l|}
\hline & A & B & SW with A & SW with B \\
\hline Breaths & 1.21 & 0 & 4.01 & 1.43 \\
\hline Instances & 0.35 & 0 & 1.84 & 0.48 \\
\hline Episodes & 0.35 & 0 & 1.08 & 0.32 \\
\hline
\end{tabular}

The social worker had only two episodes of laughter in her interview with B and they occurred within seconds of one another. B did not laugh at all. The first episode of laughter on the part of the social worker seemed to express discomfort about having expressed a personal rather than a professional opinion in response to one of the students' questions about homeschooling as a means of avoiding the vaccination requirement. The second episode, still addressing the same topic, was self-mocking, as the social worker noted a contradiction between her stated stance on homeschooling and her personal experience of it. This self-deprecating laughter presented an opportunity for a rapport-building, sympathetic response from $\mathrm{B},{ }^{50}$ but instead the student-lawyer responded with an affirmation:

B: Mmh, um, that's actually great.((TOUCHES KEYPAD; LEANS

BACK))

because that's what I was going to ^ask you.

((GESTURES ON TABLE))

Should she present, um, an incl- or a

/desire to have him lhomeschooled

if she works out some sort of situation where / that is an

option for

her- um,

would you be opposed to him being homeschooled

((SW PUSHES UP SLEEVES, LEANS FOREARMS ON TABLE))

and not being vaccinated in that case? ?2 $^{22}$

SW: Ah, you mean ^personally /would I be? Eh [@@@@]

B: $\quad$ [Right.]

SW: It is legal. I $\wedge$ understand that home school is legal.

Personally ((GESTURES TOWARD CHEST)) I, I don't believe in home schooling.

B: Okay. ((MOVES HAND FROM CHIN TO KEYBOARD; TYPES))

SW: ((ILEANS IN; TAPS TABLE)) I say that:

$<\mathbf{S}$ my brother has five kids ((NODDING))

and they're all homeschooled. S $>$

50. Self-deprecating humor has been characterized as affiliative-the type of humor that accentuates the relational and other-orientation. R.A. Martin et al., Individual Differences in Uses of Humor and Their Relation to Psychological Well-Being: Development of the Humor Styles Questionnaire, 37 J. Res. Personality 48 (2003). 
B: Right. ((NODDING))

SW:1/@@@

B: Right.

SW: \@@

and, and $\mathrm{eh}=\ldots \mathrm{so}=\ldots$, um, $\mathrm{ah}=$, yes, $<$ I mean, $>>$ you can't $<$

$\checkmark$ keep her from homeschooling <to my knowledge, her children.>

B: Mmh.

This excerpt captures every instance of laughter in the interview with $\mathrm{B}$, a stark contrast to the crescendo of laughter occurrences with A. The pattern of intervals between the social worker's instances of laughter with A suggests increasing comfort as the interview unfolds. In a fifty-one-page transcript, the social worker laughs on pages five, eight, fifteen, thirty-one, thirty-three, forty, forty-three, forty-five, forty-six, forty-seven, and fortynine.

While A laughed less than the social worker throughout, his laughter frequently provoked hers, as in the following exchange on the same topic as with $\mathrm{B}$-avoiding the school vaccination requirement, in this case making reference to the Amish as an example of a religious group whose insularity and religious conviction form the basis of their exemption:

SW: ((GESTURING)) But I mean ^ true, although the Amish live outside of our society, they live within their own society. I know this, because I

/spend a lot of time in upstate New York.

A: @@@@@

SW: And there are a lot of Amish communities, and my partner's= ah $</$ father was raised in an @Amish@ community.>

@@

He left.@

Given the sense of this pair building relational bridges through their conversation, it's interesting to note that this bond of laughter was forged in the act of critiquing a religious group to which neither belongs. ${ }^{51}$ The axiomatic idea that the most direct route to sameness is the location of a more other Other manifests here. The social worker's laughter functioned in a range of ways in her conversation with $\mathrm{A}$, from a perhaps nervous expression of breath or punctuation (e.g., "Ah, microcosm@ of the world of a $\wedge$ child.") to a kind of commentary: laughter.

51. See supra note 50 regarding the affiliative nature of self-deprecating 
A: Um, so, you mentioned that you k-((GESTURING) $)$

/you're worried about whether the home is a safe space,

/because of the caretaker that he has right now?

SW: /Well, yeah= he is four. [@@@@]

A:

[Yeah, right]

((NODDING AND WRITING)).

SW: @@ ((GESTURING)) I don't have any kids.

But I have $\wedge$ friends who have four-year-olds, /and they are pretty precocious /and super active.

The laughter after "he is four" can be read in a number of ways. It could be a nonverbal comment suggesting that it's obvious that a fouryear-old would be unsafe in such an environment, but it could also serve to soften what comes across as a reflection of generalized negative assumptions about this family that depend on more than the specific facts and circumstances of this case.

Laughter is a fitting final marker of analysis. As a paralinguistic element that reaches deeper than language and reflects something more visceral, its different expressions in the two interviews stand out. While laughter can be a forced or reflexive response to humor or irony, ${ }^{52}$ as in the homeschooling example with $\mathrm{B}$, it can also express sympathy and camaraderie ${ }^{53}$ —each breath or instance between the social worker and A seems to strengthen their rapport. At the same time, laughter can also reflect—or mask—a wide range of highly nuanced intrapersonal maneuvers such as accomplishing a task in spite of discomfort ${ }^{54}$ or building a communicative bridge with a person whose perspective or priorities diverge from one's own. ${ }^{55}$ Laughter can be a key "tell" in moments of role dissonance; even in the absence of extended sociolinguistic analysis, attention to its appearance and functioning within the context of experiential learning can be a powerful tool for exploring deeper intrapersonal layers of the work at hand.

52. See, e.g., Gregory A. Bryant et al., The Perception of Spontaneous and Volitional Laughter Across 21 Societies, 29 Psychol. ScI. 15 (2018); Elizabeth Holt, Conversation Analysis and Laughter, in The Encyclopedia of Applied Linguistics (Carole A. Chappelle ed., 1st ed. 2012); Sophie Scott, Nadine Lavan, Sinead Chen \& Carolyn McGettigan, The Social Life of Laughter, 18 Trends in Cognitive Sci. 618 (2014); Diana P. Szameitat et al., It Is Not Always Tickling: Distinct Cerebral Responses During Perception of Different Laughter Types, 53 NeuroImage 1264 (2010).

53. See, e.g., Szameitat et al., supra note 52.

54. See, e.g., id.

55. See, e.g., id. 
Before moving on to explore actor, student, and faculty perspectives on the interviews, it is useful to identify some broader characteristics of the textual record. On the whole, both students gained very similar information from the actor playing the social worker. ${ }^{56}$ The phrasing, of course, varied, as did the number of repetitions and the emphasis of particular points, but the basic facts, opinions, and priorities were largely consistent. With both students, the social worker emphasized the importance of conducting a home visit and a new psychiatric evaluation for the mother, child, and great-aunt with a psychiatrist known and trusted by the agency. Overall, Student A heard more opinion; more personal references; and ultimately, more emphatic, unqualified, or uncensored insistence on the importance of removing Jacob from the home. The cooler rapport between Student B and the social worker seemed to inhibit personal references on the social worker's part, but they did still occur in both interviews.

Given that the information gleaned in the two interviews was roughly the same, we wondered both whether B's more clipped approach was more time efficient than A's more conversational approach and whether one student lawyer seized appreciably more floor time than the other. A's interview lasted forty minutes, thirty-five seconds with 2,891 words spoken by the student and 4,609 words spoken by the actor for a combined total of 7,500 words. B's interview, by comparison, was $20 \%$ shorter at thirty-two minutes, two seconds with 4,941 words exchanged-1,789 spoken by the student and 3,152 by the actor. While B's interview was $20 \%$ shorter in length, she held the floor $17 \%$ more of the time than A did. The perceptive or interpersonal cost of B's more controlling and compressed approach was considerable, but in terms of the content of information gathered, her efficiency seemed to create no disadvantage. The ratio of words spoken by student-lawyer to words spoken by actor-social worker was 0.6 in both instances, a numerical affirmation of the more subjective observation of the similar quantity and quality of information gathered. The ratio of words spoken was the same, and the information acquired was the same: the difference was in the conversational room A created, using more

56. In terms of the facts of the case, both students heard the social worker state that Jacob was a four-year-old boy under the daytime care of his great-aunt, Oretha, who suffers from arthritis and takes medication for her condition. The social worker mentioned the name of the medication, Tramadol, with Student B only. Both heard that Oretha drinks habitually, and with both students, the constellation of concerns relating to Oretha's health, age (the social worker specified that she is eighty-seven), physical condition, (prescribed) drug and alcohol consumption were a major point of emphasis for the social worker. Student A heard a much more extended litany of potential emergencies Oretha might not be able to respond to from falls to fires to gas explosions; Student B heard less about emergencies, but still was focused on Oretha's presumed inability to respond to the needs of a young child given her age and physical condition. 
words himself to invite the social worker to greater volubility, which apparently put her at ease.

\section{B. Participant Perspectives}

\section{The Actor Perspective: The Invocation of Status ${ }^{57}$}

The actor who worked with both students reported the following with respect to her session with A: "He introduced himself. He asked about me and my work, the steps I had taken to come to my current position. His body language was slightly more casual and open." His initial approach made her feel comfortable and sure of herself. She felt that her professional opinion was being sought in addition to facts about the case. This actor felt a sense of control, in part because the lawyer seemed "sure of himself," and she felt able to be candid. She described his "energy" as "open," and said that he left "comfortable space" within which she could "contribute." She reported that he understood her role as a supervisor and solicited her opinion about strategies that would help to achieve outcomes that her office wanted. When he challenged her positions, he did so in a way that "didn't seem to disregard my experience." He remained engaged and attentive when she said things that might have seemed tangential, and this made her feel that "he was listening." She felt encouraged to "talk about [her]self," and she felt that her experience was acknowledged. He seemed concerned, and she was "happy to engage in dialogue" with him.

In addition to reporting these specifics, the actor, who is once again, out of role, a professor in a college theater department, interpreted the student's behavior in terms of theoretical work that she relies on in both teaching and performance. She said, "He ... played a lower status from the moment he came in the door which helped to make me feel sure of myself and open up." Referring at another point to A's "playing low," she said: "This helped me feel comfortable and secure in my position. The interview felt less formal. Partly this was due to the fact that in the beginning he was nervous. But that quickly fell away and he seemed interested in understanding what I was trying to say."

The concept of "playing high" and "playing low" comes from the work of Keith Johnstone, a teacher and theorist in the field of theatrical improvisation. In his landmark text Impro: Improvisation and the Theatre, ${ }^{58}$ he devotes a chapter to status positioning, a concept he presents as the amalgam of often subconscious interactive behaviors that express power and deference. In Johnstone's understanding, every behavior, glance, position of the body, presence or absence of gesture, every silence, and every utterance is an expression of status, where status is understood as something performed, rather than something inherent in the performer or in the

57. Throughout the Article, quotes from the actors outside of the simulation exercises are taken from simulation critique forms, all on file with the authors.

58. Keith Johnstone, Impro: Improvisation and the Theatre (1959). 
performer's interlocutor. ${ }^{59}$ According to Johnstone, status positioning should be understood as "something one does," 60 whether consciously or not, rather than a reflection of inherent identity. ${ }^{61}$

According to what Johnstone refers to as the seesaw principle, the status of one party can be raised by lowering the status of the other. ${ }^{62}$ As a result, if one aims to lower one's status strategically, he or she can act to raise the status of the other person: the elevation of one creates the descent of the other. ${ }^{63}$ Concomitantly, there is no neutral. Imagine the scales of justice with an impossibility of equal weight, taunting stillness in the perpetual motion of relative adjustment. By way of example, Johnstone describes "three types of status players commonly found in the teaching profession" ${ }^{4}$ : one who is likeable but unable to maintain discipline in her classroom, a second who rules an orderly classroom full of students who fear and dislike him, and a third who is beloved, engaging, and able to maintain discipline without threat, punishment, or fear on the part of her students. ${ }^{65}$ In Johnstone's experience, this type of teacher "would joke with us, and then impose a mysterious stillness. In the street he looked upright, but relaxed, and he smiled easily." 66 Johnstone reveals that the first teacher is a low-status player; the second, compulsively high status; and the third "a status expert, raising and lowering his status with great skill." 67 The status expert elevates and lowers her own status in response to-and in order to engender-actual or desired dynamics whether in a classroom, workplace or anywhere else.

The actor in our simulation returned to Johnstone's concept to describe her very different experience with $\mathrm{B}$, saying that B "played high status . . . the whole time." B's "playing high" left the actor feeling impressed by the student's intelligence and skill. As the actor put it,

I was clear on what we were doing. I was impressed by her articulation and [the] specificity of the agenda.... Her questions were very good. Clear and articulate and smart. . . . She was professional, concise, and intelligent. I felt as if she knew what she was doing.

The actor playing the social worker reiterated this observation in response to a separate question: "I felt the lawyer was very articulate, clear, bright, and knew what she was doing."

59. Id. at $37-38,72$.

60. Id. at 36 (emphasis omitted).

61. See id.

62. Id. at $37-38$.

63. Id. at 37 .

64. Id. at 35 .

65. $I d$. at $35-36$.

66. $I d$. at 35 .

67. Id. at $35-36$. 
The student lawyer's intelligence and professionalism ultimately had an inhibiting rather than an encouraging effect on the actor in role. The actor was not drawn to collaborate with B. She reported that B "seemed in a hurry" and stated, "[F] rom the beginning, the interview seemed to be very official and as if I was not a partner in it." Student B "made eye contact, which was great," but her opened laptop computer created a barrier that impaired communication. The actor reported feeling "challenged," "judged," "slightly uncomfortable," "on the spot," "defensive," and "taken a bit back by [B's] energy." Although B gave the actor an opportunity to express her views, the actor "didn't feel comfortable to do so." She "felt as if B was on a different side." 68 The actor stated that she was shown respect but said that signs of it "felt obligatory at times." The actor was left feeling that she "wouldn't work well with [B]. She seemed too distanced." Her overall impression: "[B] played very high."

\section{The Student Perspective: Playing Straight or Cagey ${ }^{69}$}

In spite of the apparent divergence in A's and B's affect and reception, they shared misgivings about the ability of child welfare workers to

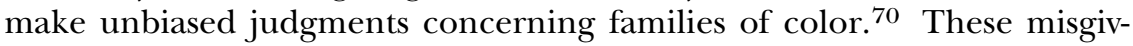

68. Again, Student B thought she was assigned to a different side for purposes of the simulation, and it's quite possible that Student B's more adversarial approach and the actor's perception thereof combined to create an interpersonal impasse that both women reacted to strongly.

69. Throughout the Article, descriptions of student attitudes and perceptions are based on written critique forms (on file with the authors), as well as our observations and the content of oral critique sessions.

70. "Racial disparities exist at every stage of child welfare decision-making." Dorothy Roberts \& Lisa Sangoi, Black Families Matter: How the Child Welfare System Punishes Poor Families of Color, ApPeAL (Mar. 26, 2018), https://theappeal.org/ black-families-matter-how-the-child-welfare-system-punishes-poor-families-of-color33ad20e2882e/ [https://perma.cc/Z6Y8-LJAD]. In 2000, for example, black children represented $36 \%$ of children in foster care, though black children constituted only $15 \%$ of the child population. Joshua Padilla \& Alicia Summers, Disproportionality Rates for Children of Color in the Foster Care System, NAT'L CounciL Juv. \& Faм. Ст. Judges (May 2011), https://ncjfcj-old.ncjfcj.org/sites/default/files /Disproportionality\%20TAB1_0.pdf [https://perma.cc/H256-KECN]. In places like New York City, nearly all families under supervision and all the children in foster care are black or brown. Roxanne Saberi \& Lisa Semel, In New York, Black Families More Likely to Be Split by Foster Care System, Al Jazeera Am. (June 25, 2015), http:/ /america.aljazeera.com/articles/2015/6/25/new-york-foster-care-system-racial-disparity.html [https://perma.cc/7NC3-TR86]. Black parents are also subjected to termination of parental rights at higher rates than white parents. See Minkyoung Song, Termination of Parental Rights and Adoption in Foster Care (2006) (unpublished Ph.D. dissertation, University of Pennsylvania), https://repository.upenn.edu/dissertations/AAI3225547 [https://perma.cc/7D9X-GPFS]. The racial disparities in the child welfare system are not because more abuse and neglect exist in black families as compared to white families. See, e.g., Donald Baumann, The Intersection of Race, Poverty, and Risk: Understanding the Decision to Provide Services to Clients and to Remove Children, 87 Child Welfare 152 (2008) (noting that caseworkers more quickly perceive black children as being at risk and in need of removal from their homes); Ira J. Chasnoff, Harvey J. Landress \& Mark E. Barrett, 
ings raised a distinct set of identity and social difference issues. Student A candidly reported in the critiques that he consciously concealed his skepticism about the social worker's positions in order to foster a collaborative relationship with her. His open questions, occasional stutter, honorific references, collegial overlapping to the point of speech in unison, and willingness to laugh seem to have been conscious parts, and unconscious byproducts, of his plan to be strategic rather than candid in the encounter. Student A told us that at times he had difficulty suppressing his sense that the social worker was biased and unreasonable. He pointed, for example, to a moment in the interview when the social worker speculated about the great-aunt caregiver's drinking habits in ways that suggested cultural bias. In fact, she engaged in such speculation in two separate instances:

SW: It might $\wedge^{\mathrm{be}}<$ the first time she's ever had a glass of sherry> ((GESTURING)) but I don't, I don't / think it is, because I'm thinking in, in, um, the re, report $<$ that I read $>$ that it's, it's, a sort of an, a, ah, something that she does every day.

A: Right. ((GESTURES))

SW: It's a habitual habit in sort of . . calming down.

$(($ GESTURING $))$ Now with the, the addition of $<$ the pain medication,> $<$ I don't know how long \she's been on the pain medication. $>$

SW: Um, there is ah, ((GESTURING)) first, her age and her= state of well-being, her health. /And if she's on pain medications

A: Mmh.

SW: and the fact that, ah, /she is consuming alcohol ((GESTURING)) during, during that

A: $\mathrm{Mmh}$.

SW: um, /while taking care of the child= there was pain medicine $=$.

$(($ GESTURING $)) /$ the fact that she'd fallen asleep.

A: Right.

The Prevalence of Illicit-Drug or Alcohol Use During Pregnancy and Discrepancies in Mandatory Reporting in Pinellas County, Florida, 332 New Eng. J. Med. 1202 ( 1990) (finding that despite similar rates of substance use between black and white pregnant women, black women were ten times more likely to be reported to child welfare authorities for substance use during pregnancy); Alan Dettlaff et al., Disentangling Substantiation: The Influence of Race, Income, and Risk on the Substantiation Decision in Child Welfare, 33 Child. \& Youth SErvs. Rev. 1630, 1630-37 (2011); Wendy G. Lane, David M. Rubin \& Ragin Monteith, Racial Differences in the Evaluation of Pediatric Fractures for Physical Abuse, 288 JAMA 1603 (2002) (finding that doctors are more likely to report injuries on black children as suspected child abuse than identical injuries on white children). 
SW: There was sherry out, there was pain medicine $=$. $\mathrm{Um}=$, that that seems-

I have a hard time believing that perhaps ((GESTURING)) it's the first time she's fallen asleep.

While we've largely considered A's listening responses supportive and sympathetic-and while they had an encouraging effect on the social worker-the overall pattern here strikes us as less engaging and more terse as the social worker moved into arguably stereotypical territory. Student A put his interlocutor's comfort above all else as a means of achieving his goal of eliciting the most extensive, thorough, and frank contributions possible from the social worker. Still, his reservations about her stance in the case were candidly expressed in his self-critique and subtly revealed in the linguistic markers. Where A's listening responses were typically affirming, when conversation reached the subject of the great-aunt's drinking they became predominantly neutral.

The linguistic markers similarly reveal Student B's suspicions that the social worker was racially biased. When her questions to the social worker involved the formulation "what would you look for" or "be looking for," they seemed to emphasize the social worker's subjectivity over her authority and to seek specifics rather than the more generalized and potentially biased comments the social worker sometimes made. Consciousness of the ways state agencies can construct or rely on narratives of black pathol$\mathrm{ogy}^{71}$ potentially informed B's desire to move from the social worker's dec-

71. The roots of the black pathology ideology arguably can be traced to anthropologist Oscar Lewis's notion of a "culture of poverty"-Lewis reprinted numerous versions of his definition of the term "culture of poverty" in short journal articles and also in the introductions to his books on family life among Mexican, Puerto Rican, and Cuban low-income neighborhoods, see, e.g., Oscar Lewis, The Culture of Poverty, 215 Scr. Am., Oct. 1966, at 19, https://pdfs.semanticscholar.org/ 3a0c/8930ed909e323dd3aa8603bfa25f9a04bf13.pdf [https://perma.cc/G4T3CEHE], and the 1965 "Moynihan Report," in which black American families were characterized as being caught up in a "tangle of pathology." See generally U.S. Dep't of Labor, Office of Policy, Planning, and Research, The Negro Family: The Case for National Action (1965), https://web.stanford.edu/ mrosenfe/ Moynihan's\%20The\%20Negro\%20Family.pdf [https://perma.cc/XZQ6-84AC]. Informed by this view of pathology, black Americans today are disproportionately penalized across the board-e.g., black immigrants are disproportionately deported for criminal offenses. Renee Feltz, Black Immigrants Much More Likely to Be Deported over Criminal Offenses, Data Shows, Guardian (Oct. 3, 2016), https:// www.theguardian.com/us-news/2016/oct/03/black-immigrants-us-deportationrates-criminal-convictions [https://perma.cc/6A54-8532]. "Black students are disproportionately suspended from class," Casey Quinlan, New Data Shows the School-toPrison Pipeline Starts as Early as Preschool, Think Progress (June 7, 2016), https:// archive.thinkprogress.org/new-data-shows-the-school-to-prison-pipeline-starts-asearly-as-preschool-80fc1c3e85be/ [https://perma.cc/U5VU-U5CT], and black adults and youth are disproportionately arrested and incarcerated. See generally Michelle Alexander, The New Jim Crow, (2010); Ta-Nehisi Coates, The Black Family in the Age of Mass Incarceration, ATLANTIC (Oct. 2015), https://www.theatlan- 
laration that they should "make sure that, you know, things are happening as they should be happening" to knowing what precisely she would be "looking for" in a home visit. The following exchange further demonstrates B's sensitivity to the potential for stereotyped remarks from the social worker:

B: What have you looked for in the past, both from the caregivers ((GESTURE)) and the child, ((GESTURE))

SW: Mmh.

B: in these sort of neglect proceedings . . ((OPEN PALM DOWN GESTURE) ) during the psych evaluations, [like]

SW:

[Sure,]

Okay.

B: what sort of information are you looking for?

SW: Well, we're not, ah$<$ S can you, can you say /a little bit more ((POINTING)) about $\mathbf{S}>$

B: Right.

SW: what, clarify what you want ...

B: Right, you said that you wanted to be very cautious and have the psych evaluation conducted by someone who knows ((GESTURE) $)$ "what to look for".

SW: Mmh.

B: Um, and so what is it that you would be looking for?

SW: ((STRAIGHTENS UP IN POSTURE)) ((B LISTENS, LEANING IN WITH AN ELBOW ON THE TABLE))

Well, okay, so perhaps .. ah, that I miscommunicated using that phrase "what to look for." ((STILL HANDS, EYELINE ABOVE B'S HEAD))

It's not necessarily in the, in the sense that we believe that there is, <we're looking to read $>$ details in, ah . . /a . certain way $=$.

Although the social worker may have felt that B was giving her a hard time in the above instance, or was generally distant throughout the interview, in the hearing, as we have noted, B advocated fervently and persuasively for rulings in accordance with the social worker's priorities in the case. B sought continued remand of the child in state custody based on

tic.com/magazine/archive/2015/10/the-black-family-in-the-age-of-mass-incarceration/403246/ [https://perma.cc/FD7M-L5U9]. In the specific context of child welfare, racial disparities exist across all aspects. See supra note 70 and accompanying text. 
the dual neglect of the caretaking arrangement and the lack of vaccination. She referred to the great-aunt as alcohol dependent and referenced the mother's "history of neglect" in taking a conscientious stand against vaccination for her child.

Student A took a similarly hard line in the hearing, referring to the mother as being "arrogant and outrageous" in her desire to maintain the caretaking arrangement with her aunt. He did, however, indicate a willingness to withdraw the allegation of neglect due to the mother's refusal to vaccinate. Ultimately, both lawyers withdrew the vaccination claim, but were able to secure modifications to the caregiving arrangement including supervision (in both cases), possible day care or preschool (Student B), and an agreement that the great-aunt would not consume alcohol and pain medication while caring for the child (Student B).

The social worker's argument and perspective may have had an impact on both student lawyers, and an arguably greater impact on the student with whom she felt less positive rapport. It is more likely, however, that the students simply followed rigid interpretations of the lawyer's duty to leave the setting of goals to the client. ${ }^{72}$ It was productive to talk with both students about this ethical obligation and to consider it in light of (1) a lawyer's duty to improve the law, ${ }^{73}$ (2) the power a lawyer has in being the client's interpreter of the law, (3) the special complexities of interacting with an agent of an institutional client, and (4) the lawyer's role as a counselor. ${ }^{74}$ Indeed, when we interviewed A after he had practiced for a time at a large corporate law firm, he told us how helpful it was to have learned to make conscious judgments about the factual grounding or ethical defensibility of client positions and, more generally, about the nuances of interactive work with clients, colleagues, counsel for opposing or collaborating parties, and supervisors.

\section{The Faculty Perspective: Cultivating Multiple Intelligences}

We began this Article by characterizing it as a reflection on how simulation courses might "open the door" to critical engagement with communication across identity differences in ways that, ultimately, both improve

72. For example, Rule 1.2 of the Model Rules of Professional Conduct states that "a lawyer shall abide by a client's decisions concerning the objectives of representation and ... shall consult with the client as to the means by which they are to be pursued.” Model Rules of Prof'l Conduct r. 1.2 (Ам. Bar Ass'n 2019).

73. The Model Rules of Professional Conduct's Preamble states: "As a public citizen, a lawyer should seek improvement of the law, access to the legal system, the administration of justice and the quality of service rendered by the legal profession.” Model Rules of Prof'l Conduct Pmbl. (Am. Bar Ass'n 2019).

74. The Model Rules of Professional Conduct Rule 2.1: "In representing a client, a lawyer shall exercise independent professional judgment and render candid advice. In rendering advice, a lawyer may refer not only to law but to other considerations such as moral, economic, social and political factors, that may be relevant to the client's situation." Model Rules of Prof'l Conduct r. 2.1 (Ам. BAR Ass'n 2019). 
the legal professional's competence and generate success with clients. As part of this specific simulation course, we considered the process and outcome in each simulation of the students' application of the Lawyering Method. As we explained, the Lawyering Method requires students to go beyond traditional syllogistic reasoning and employ other modes of analysis, including, for example, institutional and sociocultural analysis, and psychological analysis, both modes of particular relevance to the simulation events we detailed above regarding Student B.

For this simulation, we $\mathrm{e}^{75}$ went into the culminating critique with multiple questions. Addressed here are two questions that relate to the dimensions, discussed supra, and are especially relevant to the management of communication across identities. First, we were eager to understand what (beyond B's misapprehension of the social worker's role and knowledge base) had caused the social worker's discomfort with B. After all, by our account and according to the actor's written and oral critique, $\mathrm{B}$ had given a well-prepared and polished performance. Moreover, our analysis showed that B had elicited as much information as had A. She had analyzed the law with similar care and with similar conclusions. And, as we have said, B ultimately took a rather hard line in support of the agency, gaining pro-agency rulings that A did not seek or obtain. Second, given that both $\mathrm{A}$ and $\mathrm{B}$ had been strong advocates for their client, we were eager to understand how each had managed the reservations we knew that they held about the client's position. What we discovered was that social distance had caused unsuspected layers of discomfort between the social worker and $\mathrm{B}$ and between the professor and B. We also discovered that each of the student lawyers had covertly managed role dissonance and welcomed opportunities to discuss it.

As the description of the critique session with which we opened this Article makes clear, B reacted strongly to the assertion that she was "playing high." She had prepared carefully for the interview. Moreover, she had drawn on extensive experience working with clients as a volunteer at a public service organization. In her public service work, she had consciously balanced the need to inspire confidence and the need to generate levels of comfort that enabled clients to share personal and emotionally charged facts. We were suspicious of the gap between her perception of her performance-and ours-on the one hand, and the actor-client's perception on the other. Given the discrepancy, we decided to revisit the actor-client feedback for Student B in the marriage scenario.

In the marriage simulation-the other simulation in which the students participated-we were surprised to see that the actor-client, an Indian woman, had articulated a similar lack of rapport in her critique of B's work. She described feeling "a wash of discomfort throughout primarily because there was a barrage of information and legalese coming my way,

75. References to "we" and "our" for the remainder of Part II refer to Peggy Davis and Danielle Davenport. 
without enough clarification or time given for me to process the information." Her responses to various questions in the critique continued along these lines, similar lines to those around which the actor-social worker framed her critique in the later simulation with one notable exception: the reference to status.

Review of this earlier critique of B's work-which struck us as valid at the time we received it, but didn't stand out among the range of student communication styles and efforts at rapport building in the early simulation-gave us pause. Across the multiple formal and informal opportunities for feedback, the actor-social worker latched very firmly onto this notion of the lawyer B's high status as an obstacle to rapport. Because of the social distance between them, and between the actor and us as black women, we worried that this was a racialized, and therefore exaggerated, response to B's behavior. But given the strength of both actors' responses, we were forced to consider our own bias.

The incident presented an opportunity to reflect on the effect our own identities had in evaluating B's performance, in weighing the actor feedback to it, and in considering Student B's response to that feedback. Student B is a black woman training for work in a still predominantly white and male profession. ${ }^{76}$ As black women, we were especially attuned to the fact that behaviors that might be taken as markers of "playing high" were appropriate from Student B's perspective in that they denoted competence that might not be taken for granted by a counterparty in a professional setting. ${ }^{77}$ When we saw B's conversational dominance (the closed and leading questions, the steady articulation with moderately frequent filler use, the lack of honorifics, the focused efficiency, the overlapping,

76. According to the American Bar Association, close to $90 \%$ of licensed attorneys in the United States were white, while $5 \%$ were black, and close to $70 \%$ were men. Am. Bar Ass'n, ABA National Lawyer Population Survey: 10-Year Trend in Lawyer Demographics (2018), https://www.americanbar.org/content/ dam/aba/administrative/market_research/National_Lawyer_Population_ Demographics_2008-2018.pdf [https://perma.cc/T3YT-TQ4Y]].

77. As Patricia Williams has written, black people (and particularly black women) may feel a greater need than do whites for formality as "a way of enhancing trust . . . in . . . business affairs." Patricia Williams, The Alchemy of Race and Rights 147-48 (1991) (drawing on personal experience to compare her own need for a written lease lest she be seen as "unreliable, untrustworthy, hostile, angry, powerless, irrational and probably destitute" with her white, male colleague's relaxed sense that a formal lease would "introduce [alienating] distrust" into his relationship with a lessor). Williams's strategic reasons for taking a more formal approach to negotiating a lease, as described, may be analogous to Student B's strategic decision to approach the simulation in the way she did. 
and the disinclination to laugh), we thought it natural because we were focused on the identity threat that $\mathrm{B}^{78}$-and we ${ }^{79}$-routinely manage.

On reflection, we realized that our critique of B's work would have been strengthened by an earlier, and deeper, discussion of status positioning. Looking more closely at B's interview of her client in the marriage simulation, we saw a formality that may have come at the cost of building collaboration and trust. ${ }^{80}$ We might have guided B earlier to what turned out to be her exquisite appreciation of the need to show command of one's field while simultaneously establishing common ground and showing empathy.

A similar, but more complex set of issues related to identity and status faced $\mathrm{B}$ in the neglect simulation. Looking more closely at the dynamic between $\mathrm{B}$ and the social worker, we observed that the interview raised at least three potentially fraught identity issues: race, gender, and professional status. B probably was conscious of a cultural pattern of disparagement of black competence in a professional field like law. ${ }^{81}$ She probably was also aware that women are at greater risk of having their competence

78. See, e.g., Maura Cheeks, How Black Women Describe Navigating Race and Gender in the Workplace, Harv. Bus. Rev. (Mar. 26, 2018), https://hbr.org/2018/03/ how-black-women-describe-navigating-race-and-gender-in-the-workplace [https:// perma.cc/5BNE-769L] ("The women I interviewed talked a lot about having to dampen aspects of their personality to feel like they could fit into the culture of their workplace. One woman told me, 'My mentors talk to me about dimming my light. I always thought I had to bring that down to make people comfortable.' These women tended to feel that their organizations 'weren't ready' for them and they felt like they couldn't be their authentic selves in the office at the risk of making others feel uncomfortable or hurting their chances of professional advancement.").

79. See, e.g., Gabriella Gutiérrez y Muhs et al., Presumed Incompetent: The Intersections of Race and Class for Women in Academia (2012) (noting that black female law professors report being queried, questioned, and challenged by white law students, usually males, in ways that their white male colleagues are not).

80. Analogizing again to Williams's decision to use formality in negotiating a lease, discussed supra note 77, both her and Student B's strategic choices for more coolness and formality may have risked increasing levels of distrust and feelings of alienation.

81. See Ella L. J. Edmondson Bell \& Stella M. Nkomo, Our Separate Ways: Black and White Women and the Struggle for Professional Identity (2001) (discussing how black men and women regularly encounter the stereotype of "incompetent and unqualified"). While both black men and black women encounter the stereotype of "incompetent and unqualified," $i d$., black men more successfully rise to professional managerial positions, underscoring the influence of the intersecting identities as female and a racial minority. Ann M. Morrison, \& Mary Ann von Glinow, Women and Minorities in Management, 45 Ам. Psychol., 200, 200-08 (1990). 
underestimated $^{82}$ and their performance undervalued. ${ }^{83}$ Paradoxically, however, as a lawyer interacting with a social worker, B needed to manage the inappropriate but commonly perceived status difference between the two professions. At the same time, she needed to manage the tensions among doing the bidding of a client (or, more complex still, doing the bidding of a client's agent), following a client-friendly interpretation of the law, and following her sense of what the law should and could be.

What were we, as teachers-and as black female teachers-to make of this tangle of identities and of A's and B's performances in the midst of it? ${ }^{84}$ It was unacceptable to chastise B for her strategic choice to display dominance and confidence in the face of double-barreled identity threat. We shared and endorsed her sense that as a black woman in a white- and male-dominated profession she would be wise to remain conscious of a need to assert authority and foolish to fall into patterns of non-strategic deference. Indeed, we applauded her confidently assertive professional stance. We well understood that the actor's description of feeling "challenged," "judged," "slightly uncomfortable," "on the spot," "defensive," and "taken a bit back by [B's] energy" might have read to B as a racially tinged charge of being "uppity." 85 To be sure, a lawyer might be wise in many situations to assume a formal and controlling interactive stance, particularly in the more adversarial context that B had mistakenly assumed. It

82. See, e.g., Gwen Moran, How Being Underestimated Made These Women More Successful, FAsT Co. (Oct. 29, 2018), https://www.fastcompany.com/90254838/ how-being-underestimated-made-these-women-more-successful [https:// perma.cc/B5TW-V3H5] (noting that "being underestimated because of their gender is often a common phenomenon" for women leaders).

83. See, e.g., Claire Cain Miller, As Women Take over a Male Dominated Field, the Pay Drops, N.Y. Times (Mar. 18, 2016), https://www.nytimes.com/2016/03/20/upshot/as-women-take-over-a-male-dominated-field-the-pay-drops.html?_r=0 [https:/ /perma.cc/V6FW-7NET] (summarizing earnings statistics and noting that "[w]ork done by women simply isn't valued as highly"). Women report feeling isolated in corporate environments, for example, especially where most of the managers are white men; the white male culture feels inhospitable and alien to them. See, e.g., Bell \& Nкомо, supra note 81. Black women can feel particularly outside the lines; compared with the white women, black women report having fewer resources, such as network contacts, to help them fit into corporate environments. Id. They also felt greater pressure to perform better than their (mostly white) male colleagues, and were much less likely to have role models who reflected their own gender and race. $I d$.

84. In our anxiety about seeming insensitive to B's position as a black woman, we exhibited our own version of identity threat-as black people working in faculty roles we were anxious lest we be perceived as "race traitors," no longer sensitive to the slights of whites and no longer allied with the dignitary needs of blacks.

85. See Jeet Heer, Donald Trump, America's Racial Sheriff, New Republic (Nov. 27, 2017), https://newrepublic.com/article/145975/donald-trump-americas-racial-sheriff [https://perma.cc/NS8E-3ZC8] ("Sentimental depictions in literature of thankful slaves helped cement the idea that slavery was beneficial and that people of African descent were naturally servile. After the abolition of slavery, this cultural stereotype transformed into the expectation that African Americans remain obliging and obedient even when they had achieved success. To do otherwise was to be "uppity.'”). 
was possible that A's more relaxed stance during the social worker interview reflected a relative lack of concern rather than a strategic choice: A was headed for a career that seemed remote from the field of family practice, while B intended to remain in the public interest sector and work in an area in which family law is often implicated.

After the session described at the beginning of this Article, we asked B to focus on the benefits of inspiring collaboration with one who could serve as a source of facts and as an agent in facilitating resolutions. ${ }^{86} \mathrm{Al}-$ though B had come to the course with considerable experience dealing with clients, she had less experience dealing with collaborators from other professions. While she initially resented the critique that she was "playing high" and understandably took it as a racialized charge of uppity behavior, she seemed to welcome the invitation to think separately about techniques for interacting with potentially collaborating professionals. Having made this distinction, B was able to consider sophisticated, strategically tailored interactive choices that one might make with the upscale professional client whom she had interviewed in the first simulation, the social worker whom she had interviewed in the second simulation, and the public interest clients whom she encountered in her volunteer work. B is a brilliant and tough young woman with an eye for subtlety. She was admirable in her ability to appreciate and take to heart the differing sensitivities required in interpersonal dealings across professional and social positions.

There was a separate status-related lesson for us as teachers. Feedback from A and B's classmates helped us to appreciate additional pressures that both A and B might have felt, but that B might have felt more keenly, in the course and in the simulation. In a larger law school setting - and in a larger culture-where status and formality are prized and relational work is often trivialized, it is easy for students to assume that playing high will be rewarded by faculty. It is possible that $\mathrm{B}$ assumed a more formal stance in order to please her teachers, and it is possible that this was a more charged effort given the rare opportunity B had to work with faculty who were also black and female. It is also possible that anxieties or blind spots related to our own identity and status inhibited us from addressing the relational opportunities that were lost when B assumed a decidedly business-like interactive style in the first simulation. We should have been more attuned to the range of relational complexities involved in functioning as black women in superordinate roles.

86. B had been unusually sensitive to the need for this kind of collaboration. In a proposed order resolving the case, she had pledged the agency's cooperation in finding day care for the mother. Building on leverage this offer gave her, she pledged the agency's cooperation in getting the child vaccinated in accordance with any requirements the selected day care establishment maintained. 


\section{Conclusion}

What is the teacher to make of all of this? The learning process described above is labor intensive and expensive. It requires a willingness on the part of students, actors, and faculty to tread emotionally difficult terrain. To return to the moment from the critique session depicted at the beginning of the Article, in this very brief interaction there are infinite opportunities to build inter- and intrapersonal awareness. What would have been the most effective means of communicating the status point? Was the reference to playing high unfairly loaded? Completely apt? Something in between? How could actor and student both have evaluated the initial intention behind and ultimate impact of their words? What was the best way to address the gem of useful feedback swathed in a predictably offensive formulation? For us, as faculty, what is at stake in the decision to wade into these sensitive waters?

The questions are endless, and the answers can only be partial. Our students profited from having a videotaped record of their performances and faculty, peer, and actor feedback. We subsequently profited from having candid feedback from students and systematic language-based analyses of their performances. We also profited from mixing the disciplines of theater and law; the role of status positioning in interactive work took on new meaning as we examined it through the lens of theater studies. But the development of the students' relational skills depended most on their having a simulation context within which they were regularly focused onand assessed in terms of-the interpersonal dimensions of lawyering work. A learning environment that privileges interpersonal analysis and integrates it meaningfully with doctrinal analysis is optimal for the development of professional excellence. The overarching lesson is that we are all immersed in, and must never imagine ourselves as being above, the emotional consequences of living within mixed sets of inevitable and chosen identities. 
APPENDIX

Transcription Guide

Line breaks represent intonation units

\begin{tabular}{|c|c|}
\hline / & $\begin{array}{l}\text { speaker's intonation rises from the slash to the end of the line } \\
\text { (or to the next slash) }\end{array}$ \\
\hline$\backslash$ & $\begin{array}{l}\text { speaker's intonation falls from the slash to the end of the line } \\
\text { (or to the next slash) }\end{array}$ \\
\hline [ ] & overlapping \\
\hline$=$ & elongated word (symbol placed at end of word) \\
\hline$\wedge$ & $\begin{array}{l}\text { increase in pitch of a single word (symbol placed at start of } \\
\text { word) }\end{array}$ \\
\hline$((\mathrm{CAPS}))$ & behavior description \\
\hline$@$ & beat or "syllable" of laughter \\
\hline - & interruption \\
\hline$\ldots$ & pause of less than three seconds \\
\hline$\cdots$ & $\begin{array}{l}\text { slightly shorter pause; also used to indicate a thought that } \\
\text { trails off }\end{array}$ \\
\hline$\ldots$ & briefest pause \\
\hline italics & emphasis \\
\hline “ ” & quotations or a shift in voice \\
\hline underline & increased volume \\
\hline$<\mathbf{S} \quad \mathbf{S}>$ & lower volume; softer speech with more breath \\
\hline$<>$ & faster pace than established baseline \\
\hline$><$ & slower pace than established baseline \\
\hline
\end{tabular}

